\title{
Biological Synthesis of Silver Nanoparticles by Cell-Free Extract of Spirulina platensis
}

\author{
Gaurav Sharma, ${ }^{1}$ Nakuleshwar Dut Jasuja, ${ }^{1}$ Manoj Kumar, ${ }^{2}$ and Mohammad Irfan Ali ${ }^{1}$ \\ ${ }^{1}$ School of Sciences, Suresh Gyan Vihar University, Rajasthan 302017, India \\ ${ }^{2}$ Marine Biotechnology Laboratory, Department of Botany, University of Delhi, Delhi, India
}

Correspondence should be addressed to Nakuleshwar Dut Jasuja; nakuljasuja@gmail.com

Received 23 July 2015; Revised 25 October 2015; Accepted 26 October 2015

Academic Editor: Dong Kee Yi

Copyright (C) 2015 Gaurav Sharma et al. This is an open access article distributed under the Creative Commons Attribution License, which permits unrestricted use, distribution, and reproduction in any medium, provided the original work is properly cited.

\begin{abstract}
The present study explores biological synthesis of silver nanoparticles (AgNPs) using the cell-free extract of Spirulina platensis. Biosynthesised AgNPs were characterised by UV-Vis spectroscopy, SEM, TEM, and FTIR analysis and finally evaluated for antibacterial activity. Extracellular synthesis using aqueous extract of S. platensis showed the formation of well scattered, highly stable, spherical AgNPs with an average size of $30-50 \mathrm{~nm}$. The size and morphology of the nanoparticles were confirmed by SEM and TEM analysis. FTIR and UV-Vis spectra showed that biomolecules, proteins and peptides, are mainly responsible for the formation and stabilisation of AgNPs. Furthermore, the synthesised nanoparticles exhibited high antibacterial activity against pathogenic Gram-negative, that is, Escherichia coli, MTCC-9721; Proteus vulgaris, MTCC-7299; Klebsiella pneumoniae, MTCC9751, and Gram-positive, that is, Staphylococcus aureus, MTCC-9542; S. epidermidis, MTCC-2639; Bacillus cereus, MTCC-9017, bacteria. The AgNPs had shown maximum zone of inhibition (ZOI) that is $31.3 \pm 1.11 \mathrm{in} P$. vulgaris. Use of such a microalgal system provides a simple, cost-effective alternative template for the biosynthesis of nanomaterials of silver in a large scale that could be of great use in biomedical applications.
\end{abstract}

\section{Introduction}

Particles with a size up to $100 \mathrm{~nm}$ are usually referred to as nanoparticles. Nanoparticles exhibit completely new or improved properties, based on specific characteristics, such as grain size, distribution, morphology, and higher surface to volume ratio if compared with larger particles of the bulk material [1]. A specific surface area is relevant to catalytic reactivity and other related properties, such as antimicrobial activity in silver nanoparticles (AgNPs).

Biological effectiveness of NPs enhances due to increase in specific surface area and surface energy [2]. Silver has long been documented as having an inhibitory effect on many bacterial strains and microorganisms commonly present in medical and industrial processes [3]. AgNPs proved to be effective as an antimicrobial agent even at a very low concentration and they inhibit the growth of antibiotic resistant bacteria. AgNPs interact with membrane proteins and DNA of bacteria, which have sulphur and phosphorous complex that have high affinity towards AgNPs [4].
The most widely used and known applications of silver and AgNPs prevent the infection of burns and open wounds in the medical industry and include Clinical Ultrasound Gel and topical ointments and creams [5]. Other widely used applications are medical devices and implants prepared with silver-impregnated polymers. In addition, silver containing consumer products, such as colloidal silver gel and silver embedded fabrics, are now used in sporting equipment [6]. AgNPs are used in low doses for antimicrobial treatment in comparison to standard antimicrobial agents [7].

Production of NPs may be achieved through different methods. Chemical methods are the most popular methods for the production of NPs. However, chemical methods cannot evade the use of toxic chemicals in the synthesis protocol. Since noble metal NPs, such as gold, silver, and platinum, are widely applied to human contact areas, there is a growing need to develop environmentally benign protocol of NPs synthesis that avoids the use of toxic chemicals. Biological methods of NPs synthesis using bacteria $[2,8]$, fungi $[9$, 
10], plants [11-14], algae [15-17], sea weed [18], and lichen [19] have been recommended as ecofriendly alternatives to chemical and physical process.

Attachment of nanoparticles by cell wall of bacteria would be due to negative charges and specific functional groups on the bacterial surface. AgNPs after penetration into the bacterial cell may disturb the rigidity of cell wall or lipopolysaccharides membrane and inactivate enzymes functioning and their transport system and generation of $\mathrm{H}_{2} \mathrm{O}_{2}$ which results in bacterial death [20].

The synthesis of NPs of specific composition, selfassembly, and size is one of the most challenging areas of nanotechnology as it is strongly influenced by experimental conditions, the kinetics of interaction of metal ions with reducing agents, and adsorption processes of the stabilizing agent with metal NPs [10].

Among the microorganisms, microalgae have a tremendous role in bioremediation of toxic and precious metals and their biotransformation to different nontoxic forms [21]. They not only accumulate metals by chelation and chemical transformation, but are also reported to produce biomineral structures and metal NPs. However, most microorganisms that have been reported for synthesis of AgNPs are pathogenic to either plants or humans. So, over the years, researchers have turned to nonpathogenic microorganisms. Among the blue-green algae (cyanobacteria), Anabaena, Calothrix, Leptolyngbya, and Nostoc ellipsosporum have been reported to synthesise intracellular gold, silver, palladium, and platinum NPs [7]. The green microalga $C$. vulgaris has also been reported to produce gold, platinum, palladium, ruthenium, rhodium, and iridium nanoparticles, whereas the cell-free extract efficiently produces gold and silver nanoplates intracellularly [22]. Extracellular AgNP synthesis has been reported for the boiled extract of the brown seaweed Padina tetrastromatica [23].

S. platensis is a free floating filamentous cyanobacterium characterised by cylindrical, multicellular trichomes in an open, left-hand helix. It occurs naturally in tropical and subtropical lakes with high $\mathrm{pH}$ and high concentrations of carbonate and bicarbonate. In present study, we aim to test the ability of cell-free extracts of $S$. platensis to produce AgNPs in an aqueous system.

\section{Materials and Methods}

2.1. Microorganism and Culture Condition. The experimental organism S. platensis was isolated from Jal Mahal, Jaipur, Rajasthan (India), cultivated in Zarrouk's medium [24], under different temperature, and illuminated with white fluorescent lamps at a light intensity of 2,000 lux (Sharma et al. 2014). Conical flasks of $250 \mathrm{~mL}$ capacity were prepared containing $100 \mathrm{~mL}$ S. platensis culture and were shaken gently thrice a day to avoid clumping and enhance the growth.

2.2. Preparation of Microalgal Extract. Typically, $5 \mathrm{~g}$ (dry weight) S. platensis biomass was suspended in $100 \mathrm{~mL}$ of double distilled sterile water for $15 \mathrm{~min}$ at $100^{\circ} \mathrm{C}$ in an Erlenmeyer flask. After boiling, the mixture was cooled and centrifuged at $10,000 \mathrm{rpm}$ for $15 \mathrm{~min}$. Supernatant was collected and was stored at $4^{\circ} \mathrm{C}$ for further analysis.

2.3. Biosynthesis of Silver Nanoparticles. In the typically synthesis process of silver nanoparticles, add $2 \mathrm{~mL}$ of pure microalgal extract dropwise into the $100 \mathrm{~mL}$ of $1 \mathrm{mM}$ of silver nitrate solution in $250 \mathrm{~mL}$ conical flask. The reaction mixture was kept at $60^{\circ} \mathrm{C}$ for 10 min under constant mechanical stirring. It was observed that reduction of $\mathrm{Ag}$ ions into AgNPs completed within $10 \mathrm{~min}$, indicating rapid synthesis of AgNPs, and $\mathrm{pH}$ remains within 4.7-5.0 during the period of reaction. The colour change was noted and nanoparticles formation was monitored using UV-Vis spectrophotometer. The synthesised silver nanoparticles were centrifuged at $15,000 \mathrm{rpm}$ for $20 \mathrm{~min}$ at $4^{\circ} \mathrm{C}$, and discard the supernatant to collect the pellet. The pellet was washed with distilled water for several times to remove impurities and 90\% ethanol to get pure AgNPs powder.

2.4. Characterisation of Prepared Nanoparticles. The characterisation of AgNPs was carried out by surface plasmon resonance band using a UV-Visible spectroscopy 1800 of Shimadzu, Kyoto, Japan. Micrograph of AgNPs was obtained by scanning electron microscope of SEM-EVO 18, Carl Zeiss $30 \mathrm{KeV}$ SEM. TEM micrograph of the AgNPs was observed using the TEM instrument of TEM-Tecni G2-S twin FEI $200 \mathrm{KeV}$ TEM. TEM device conducted at an increasing voltage of $200 \mathrm{kv}$. The FTIR spectrum was recorded on FTIRShimadzu IR Affinity 1 . All measurements were carried out in the range of $400-4,000 \mathrm{~cm}^{-1}$ at a resolution of $4 \mathrm{~cm}^{-1}$ (Figure 2).

2.5. Antibacterial Activity of AgNPs. A turbid liquid sample of each bacterial strain with an OD of McFarland of 0.5 $\left(1 \times 10^{8} \mathrm{CFU} / \mathrm{mL}\right)$ was prepared in an isotonic $\mathrm{NaCl}(0.85 \%)$ solution. Furthermore, this solution was diluted ten times $\left(1 \times 10^{7} \mathrm{CFU} / \mathrm{mL}\right)$ and used as inoculums. $100 \mu \mathrm{L}$ of bacterial suspension was prepared and inoculated on Mueller-Hinton Agar-II (MHA-II) plates by spread plate technique. The sterile disc of $6 \mathrm{~mm}$ in diameter (Hi-Media Laboratories Pvt. Ltd.) was impregnated with $50 \mu \mathrm{L}$ of $1 \mathrm{mg} / \mathrm{mL}$ solution of nanoparticles in deionised water. The discs were evaporated at room temperature for 24 hours. Aqueous extract of deionised water was used as negative control and gentamicin $(10 \mu \mathrm{g} / \mathrm{disc})$ was used as positive control. The discs were gently pressed on MHA Petri Plates and incubated at $37^{\circ} \mathrm{C}$ for 24 hours. The zone of inhibition in the diameter of each disc was measured in millimetre $(\mathrm{mm})$ using a Hi-Media Laboratories Pvt. Ltd. zone scale. The experiments were done in four replicates and mean values of $\mathrm{ZOI}$ were reported.

The AgNPs prepared by S. platensis were used to evaluate antibacterial activity against Gram (-) and Gram (+) bacteria (Escherichia coli, MTCC-9721; Proteus vulgaris, MTCC-7299; Klebsiella pneumoniae, MTCC-9751; Staphylococcus aureus, MTCC-9542; S. epidermidis, MTCC-2639; Bacillus cereus, 


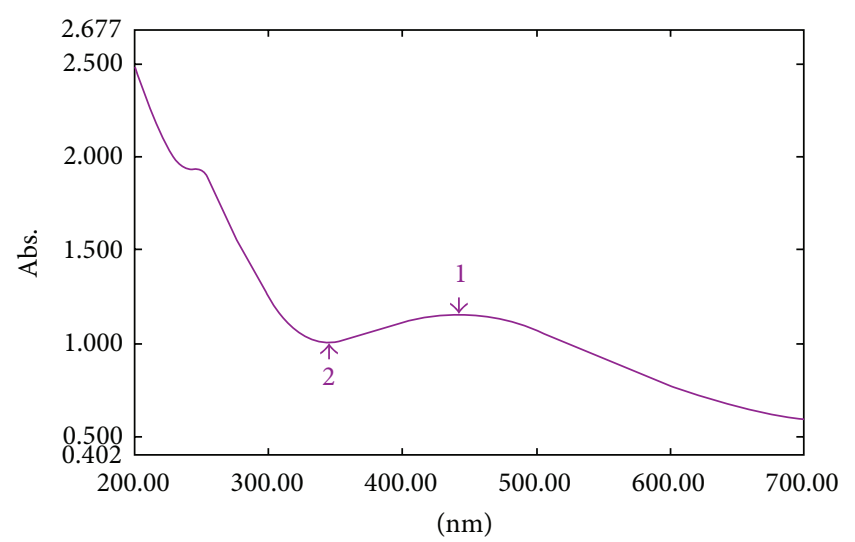

Figure 1: UV-Vis absorption spectra of AgNPs synthesised from $S$. platensis.

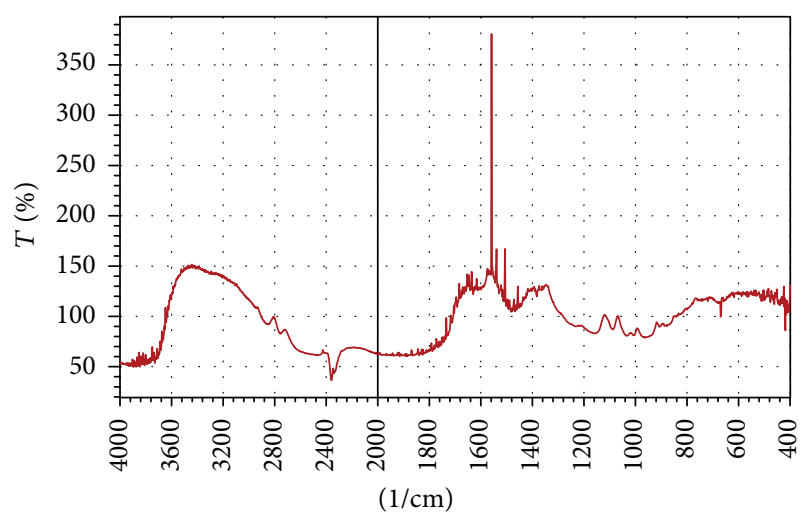

FIGURE 2: FTIR images of AgNPs generated using cell-free extracts of S. platensis.

MTCC-9017) on MHA-II plates by Kirby-Bauer disk diffusion method [25].

\section{Results and Discussion}

In this study, biological synthesis of AgNPs has been shown from cell-free aqueous extracts of $S$. platensis. These extracts when interacting with the silver nitrate salt solution form a dark brown solution due to the reduction of the silver ion to AgNPs followed by a colour change indicating the biotransformation of ionic silver to reduced silver and the subsequent formation of AgNPs in an aqueous medium. This reaction results in the biosynthesis of AgNPs showed by a colour change to dark brown from the light yellow seen at the beginning of the reaction (Figure 3). The colour change was monitored visually and the peak at $437 \mathrm{~nm}$ in the UVvisible spectra indicated the presence of AgNPs which may be due to the excitation of surface plasmon vibrations in AgNPs (Figure 1).

The morphological characteristics of biosynthesised AgNPs were studied by scanning electron microscope, using an instrument of SEM-EVO 18, Carl Zeiss $30 \mathrm{KeV}$ SEM
(Figure 4(a)). The TEM images showed that most of the particles are spherical in shape and do not create big agglomerates which indicated the monodispersed nature of NPs stabilised by a capping agent. The TEM images revealed that AgNPs are in the range of 30-50 $\mathrm{nm}$ (Figure 4(b)).

3.1. FTIR Spectrum Analysis. The FTIR spectrum of the AgNPs produced by cell-free extracts of $S$. platensis is shown in Figure 2. This spectrum shows the presence of band at 1533.89, 1558.48, 1639.49, 1652.99, and $3510.44 \mathrm{~cm}^{-1}$ corresponding to monosubstituted amide, nitro, primary amide, carboxylic, and alcohol group, respectively. The band at $1448.54 \mathrm{~cm}^{-1}$ is due to methylene scissoring vibrations present in the proteins. Largely, the observation confirms the presence of protein in AgNPs. FTIR spectroscopic study has confirmed that the monosubstituted amide of proteins has the stronger ability to bind metal, so that the proteins could most possibly form a coat covering the metal nanoparticles to prevent agglomeration of the particles and stabilizing in the medium. This data suggests that the biological molecules could probably perform the reduction and stabilisation of the AgNPs in the aqueous medium. These results confer the work of Awwad et al. [13].

3.2. Antibacterial Activity of Ag Nanoparticles. Table 1 showed the four replicates experiments of zone of inhibition $(\mathrm{mm})$ around the disc with cell-free aqueous extracts mediated synthesised silver AgNPs. The study revealed that AgNPs $(50 \mu \mathrm{g} / \mathrm{disk})$ had shown maximum inhibitory effect against Proteus vulgaris, MTCC-7299 and Staphylococcus aureus, MTCC-9542, that is, $31.3 \pm 1.11$ and $31.0 \pm 0.71$, followed by Klebsiella pneumoniae, MTCC-9751 (25.0 \pm 0.91$)$; Escherichia coli, MTCC-9721 (24.3 \pm 0.48$)$; Bacillus cereus, MTCC-9017 (24.3 \pm 0.75$)$; and S. epidermidis, MTCC-2639 $(20.0 \pm 0.41)$ as compared to gentamicin (+ control) (ZOI$22.0 \mathrm{~mm}$ ), deionised water (- control) (ZOI- 0.0), S. platensis extracts (ZOI- $8.0 \mathrm{~mm}$ ), and $1 \mathrm{mM}$ silver nitrate solution (ZOI- $10.0 \mathrm{~mm}$ ) against Proteus vulgaris (Figures 5(a)-5(f) and 6). The formations of free radicals from the surface of the silver nanoparticles were responsible for the antibacterial function. In addition, excess formation of reactive oxygen species (ROS) may lead to a breakdown of membrane function and increased permeability of the cell membrane or leakage of cell matters and morphological changes of bacterial cells and growth inhibition [26]. The charge of bacterial cell wall is negative because of dissociation of carboxylic groups on the cell surface [27]. Weak positive charges present on AgNPs are attracted towards negative charges [28]. In contrast, Sondi and Salopek-Sondi [29] suggested that the antibacterial effects of AgNPs on bacteria depended on the concentration of AgNPs and closely related with the development of "pits" on cell wall of bacteria. AgNPs interact with the thiol groups of bacterial proteins and may retard the replication of DNA [30]. It is consistent to state that binding of the nanoparticles to the bacteria depends on the surface area available for interaction. Nanoparticles have larger surface area available for interaction which enhances bactericidal effect than the large sized particles; 
TAble 1: Antibacterial activity of AgNPs.

\begin{tabular}{|c|c|c|c|c|c|c|c|c|}
\hline \multirow{2}{*}{$\begin{array}{l}\text { Bacterial strain } \\
\text { Escherichia coli, MTCC-9721 }\end{array}$} & \multicolumn{4}{|c|}{$\begin{array}{c}\text { AgNPs }(1 \mathrm{mg} / \mathrm{mL}) \\
(\mathrm{ZOI} \text { in } \mathrm{mm})\end{array}$} & \multirow{2}{*}{$\begin{array}{l}\text { Mean } \pm \text { SE } \\
24.3 \pm 0.48\end{array}$} & \multirow{2}{*}{$\begin{array}{c}\text { Gentamicin }(+) \\
\text { Control (ZOI in mm) } \\
28\end{array}$} & \multirow{2}{*}{$\begin{array}{l}\text { S. platensis extracts } \\
\text { (ZOI in } \mathrm{mm}) \\
12\end{array}$} & \multirow{2}{*}{$\begin{array}{c}\mathrm{AgNO}_{3}(1 \mathrm{mM}) \\
(\mathrm{ZOI} \text { in } \mathrm{mm}) \\
15\end{array}$} \\
\hline & 24 & 23 & 25 & 25 & & & & \\
\hline Proteus vulgaris, MTCC-7299 & 30 & 32 & 34 & 29 & $31.3 \pm 1.11$ & 22 & 8 & 10 \\
\hline Klebsiella pneumoniae, MTCC-9751 & 26 & 27 & 24 & 23 & $25.0 \pm 0.91$ & 16 & 8 & 11 \\
\hline Staphylococcus aureus, MTCC-9542 & 30 & 33 & 30 & 31 & $31.0 \pm 0.71$ & 25 & 9 & 12 \\
\hline S. epidermidis, MTCC-2639 & 21 & 20 & 19 & 20 & $20.0 \pm 0.41$ & 24 & 9 & 11 \\
\hline Bacillus cereus, MTCC-9017 & 23 & 25 & 26 & 23 & $24.3 \pm 0.75$ & 10 & 8 & 9 \\
\hline
\end{tabular}

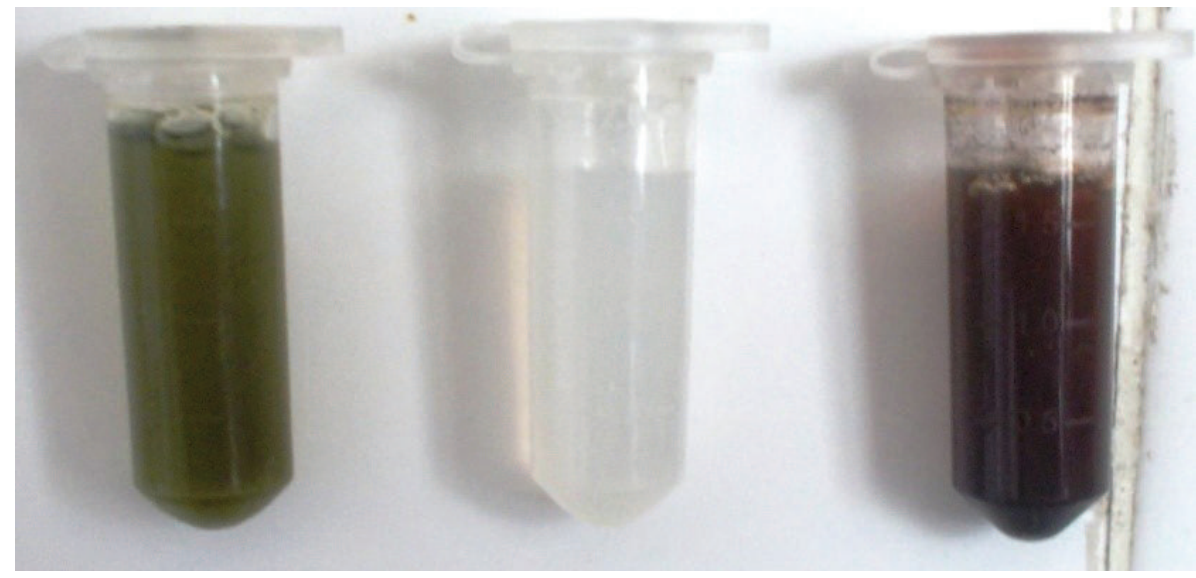

(a)

(b)

(c)

Figure 3: The pictures show the (a) S. platensis extracts, (b) $\mathrm{AgNO}_{3}$ solution, and (c) AgNPs solution.

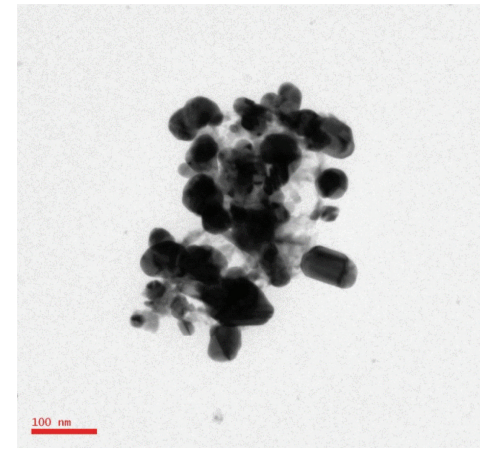

(a)

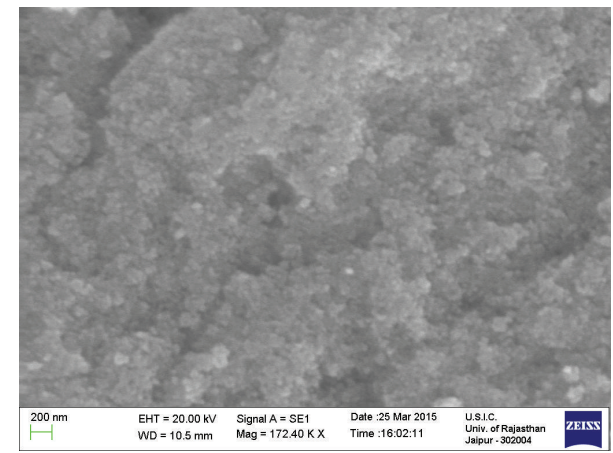

(b)

FIGURE 4: (a) The SEM images and (b) TEM image of AgNPs synthesised by cell-free extracts of S. platensis.

hence AgNPs exhibit more toxicity to the microorganism [27].

\section{Conclusion}

It is concluded that the cell-free aqueous extracts produce stable AgNPs by reduction of aqueous $\mathrm{Ag}^{+}$ions in AgNPs.
The utilisation of S. platensis biomass has various advantages like easy cultivation and availability. This biological method approach toward the synthesis of AgNPs has numerous benefits, that is, nontoxicity, cost effectiveness, rapid reduction, and economic viability. Future prospects of this research would be large scale production of AgNPs using S. platensis and ascertaining its efficacy against extensive spectrum of 


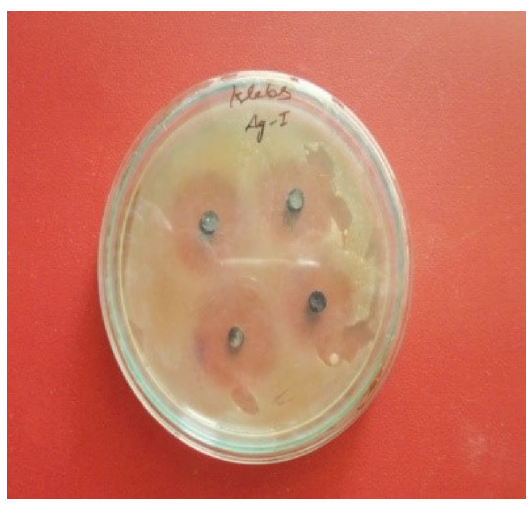

(a)

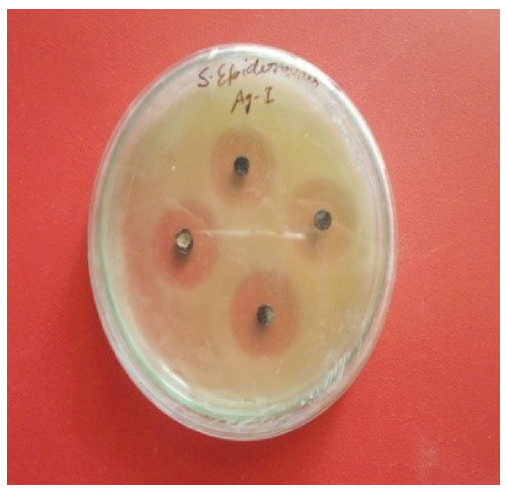

(d)

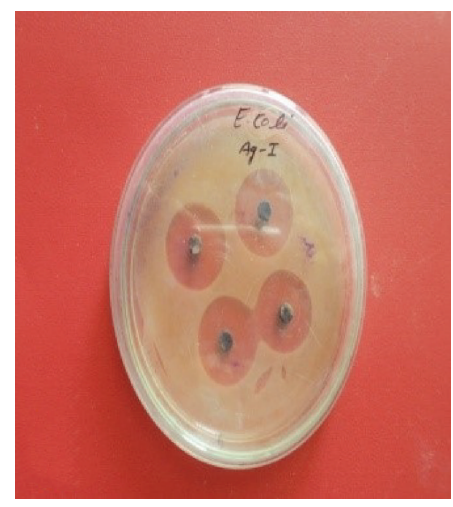

(b)

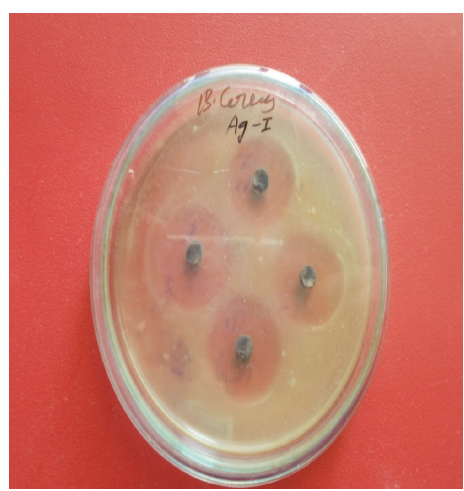

(e)

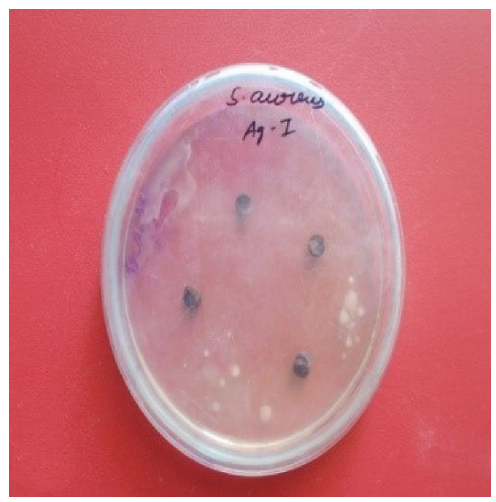

(c)

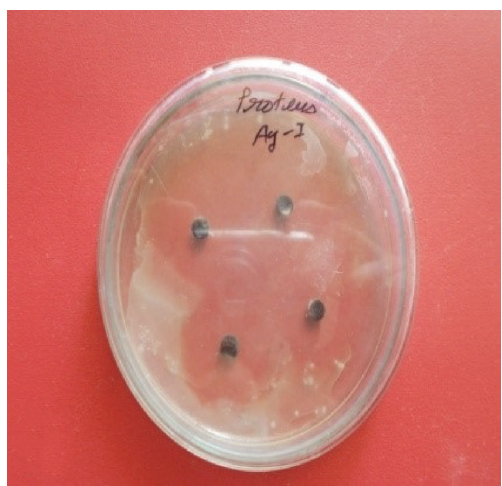

(f)

Figure 5: (a-f) Antibacterial activities of AgNPs against (a) Klebsiella pneumoniae, (b) Escherichia coli, (c) Staphylococcus aureus, (d) S. epidermidis, (e) Bacillus cereus, and (f) Proteus vulgaris.

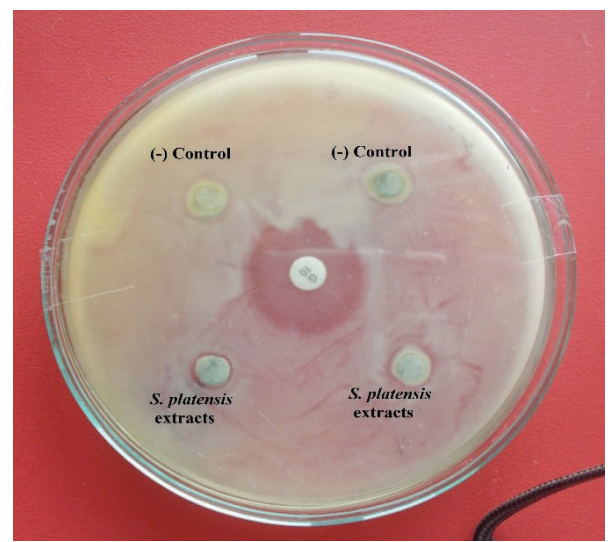

Figure 6: Antibacterial activities of gentamicin (+ control), deionised water (- control), and S. platensis extracts against Proteus vulgaris.

microbial population. Further investigations would involve covering the potency of $S$. platensis to synthesise silver nanoparticles.

\section{Conflict of Interests}

The authors declare that there is no conflict of interests regarding the publication of this paper.

\section{Acknowledgments}

The authors are sincerely thankful to Mr. Sunil Sharma, Chancellor, and Dr. Sudhanshu Sharma, Chief Mentor of Suresh Gyan Vihar University, Jaipur, for providing a platform for this research. The authors are also thankful to USIC, CCT, University of Rajasthan, Jaipur.

\section{References}

[1] G. Sharma, N. D. Jasuja, M. I. Ali, and S. C. Joshi, "A review on nanomedicinal and nanosensing potential of nanoparticles," International Journal of Biological Chemistry, vol. 8, no. 2, pp. 58-84, 2014.

[2] B. Nair and T. Pradeep, "Coalescence of nanoclusters and formation of submicron crystallites assisted by Lactobacillus strains," Crystal Growth and Design, vol. 2, no. 4, pp. 293-298, 2002.

[3] D. D. Merin, S. Prakash, and B. V. Bhimba, "Antibacterial screening of silver nanoparticles synthesized by marine micro algae," Asian Pacific Journal of Tropical Medicine, vol. 3, no. 10, pp. 797-799, 2010.

[4] S. Arokiyaraj, M. V. Arasu, S. Vincent et al., "Rapid green synthesis of silver nanoparticles from Chrysanthemum indicum L and its antibacterial and cytotoxic effects: an in vitro study," International Journal of Nanomedicine, vol. 9, no. 1, pp. 379-388, 2014.

[5] Y. He, Z. Du, H. Lv et al., "Green synthesis of silver nanoparticles by Chrysanthemum morifolium Ramat. Extract and their 
application in clinical ultrasound gel," International Journal of Nanomedicine, vol. 8, pp. 1809-1815, 2013.

[6] S. Rajeshkumar, C. Kannan, and G. Annadurai, "Green synthesis of silver nanoparticles using marine brown algae Turbinaria conoides and its antibacterial activity," International Journal of Pharma and Bio Sciences, vol. 3, no. 4, pp. 502-510, 2012.

[7] G. Sharma, N. D. Jasuja, R. Rajgovind, P. Singhal, and S. C. Joshi, "Synthesis, characterization and antimicrobial activity of Abelia grandiflora assisted AgNPs," Journal of Microbial and Biochemical Technology, vol. 6, no. 5, pp. 274-278, 2014.

[8] T. N. V. K. V. Prasad and E. K. Elumalai, "Biofabrication of Ag nanoparticles using Moringa oleifera leaf extract and their antimicrobial activity," Asian Pacific Journal of Tropical Biomedicine, vol. 1, no. 6, pp. 439-442, 2011.

[9] K. Vahabi, G. A. Mansoori, and S. Karimi, "Biosynthesis of silver nanoparticles by fungus Trichoderma reesei," Insciences, vol. 1, no. 1, pp. 65-79, 2011.

[10] V. Ganesan, J. A. Devi, A. Astalakshmi, P. Nima, and A. Thangaraja, "Eco-friendly synthesis of silver nanoparticles using a sea weed, Kappaphycus alvarezii (Doty)," International Journal of Engineering and Advanced Technology, vol. 2, no. 5, 2013.

[11] R. Geethalakshmi and D. V. Sarada, "Gold and silver nanoparticles from Trianthema decandra: synthesis, characterization, and antimicrobial properties," International Journal of Nanomedicine, vol. 7, pp. 5375-5384, 2012.

[12] R. Komal and V. Arya, "Biosynthesis and characterization of silver nanoparticles from aqueous leaf extracts of Carica papaya and its antibacterial activity," International Journal of Nanomaterials and Biostructures, vol. 3, no. 1, pp. 17-20, 2013.

[13] A. M. Awwad, N. M. Salem, and A. O. Abdeen, "Green synthesis of silver nanoparticles using carob leaf extract and its antibacterial activity," International Journal of Industrial Chemistry, vol. 4, article 29, 2013.

[14] K. Paulkumar, G. Gnanajobitha, M. Vanaja et al., "Piper nigrum leaf and stem assisted green synthesis of silver nanoparticles and evaluation of its antibacterial activity against agricultural plant pathogens," The Scientific World Journal, vol. 2014, Article ID 829894, 9 pages, 2014.

[15] S. Sharma, A. Ahmad, A. Prakash, V. N. Singh, A. K. Ghosh, and B. R. Mehta, "Synthesis of crystalline Ag nanoparticles (Agnps) from microorganisms," Materials Sciences and Applications, vol. 1, no. 1, pp. 1-7, 2010.

[16] J. Jenaa, N. Pradhana, B. P. Dashb, L. B. Suklaa, and P. K. Pandaa, "Biosynthesis and characterization of silver nanoparticles using microalga Chlorococcum humicola and its antibacterial activity," International Journal of Nanomaterials and Biostructures, vol. 3, no. 1, pp. 1-8, 2013.

[17] P. J. Shiny, A. Mukherjee, and N. Chandrasekaran, "Marine algae mediated synthesis of the silver nanoparticles and its antibacterial efficiency," International Journal of Pharmacy and Pharmaceutical Sciences, vol. 5, no. 2, pp. 239-241, 2013.

[18] P. K. Dhanalakshmi, R. Azeez, R. Rekha, S. Poonkodi, and T. Nallamuthu, "Synthesis of silver nanoparticles using green and brown seaweeds," Phykos, vol. 42, no. 2, pp. 39-45, 2012.

[19] R. Mie, M. W. Samsudin, L. B. Din, A. Ahmad, N. Ibrahim, and S. N. A. Adnan, "Synthesis of silver nanoparticles with antibacterial activity using the lichen Parmotrema praesorediosum," International Journal of Nanomedicine, vol. 9, no. 1, pp. 121-127, 2013.

[20] N. D. Jasuja, D. K. Gupta, M. Reza, and S. C. Joshi, "Green Synthesis of AgNPs Stabilized with biowaste and their antimicrobial activities," Brazilian Journal of Microbiology, vol. 45, no. 4, pp. 1325-1332, 2014.

[21] M. J. Firdhouse and P. Lalitha, "Green synthesis of silver nanoparticles using the aqueous extract of Portulaca oleracea (L.)," Asian Journal of Pharmaceutical and Clinical Research, vol. 6, no. 1, 2012.

[22] T. Luangpipat, I. R. Beattie, Y. Chisti, and R. G. Haverkamp, "Gold nanoparticles produced in a microalga," Journal of Nanoparticle Research, vol. 13, no. 12, pp. 6439-6445, 2011.

[23] P. Jegadeeswaran, R. Shivaraj, and R. Venckatesh, "Green synthesis of silver nanoparticles from extract of Padina tetrastromatica leaf," Digest Journal of Nanomaterials and Biostructures, vol. 7, no. 3, pp. 991-998, 2012.

[24] C. Zarrouk, Contribution a l'etuded'unecyanophycee. Influence de divers facteurs physiques etchimiques sur la croissance et photosynthese de Spirulina maxima (Setch et Gardner), Geitler [Ph.D. thesis], University of Paris, Paris, France, 1966.

[25] A. W. Bauer, W. M. Kirby, J. C. Sherris, and M. Turck, "Antibiotic susceptibility testing by a standardized single disk method," American Journal of Clinical Pathology, vol. 45, no. 4, pp. 493496, 1966.

[26] E. Mendis, N. Rajapakse, H.-G. Byun, and S.-K. Kim, "Investigation of jumbo squid (Dosidicus gigas) skin gelatin peptides for their in vitro antioxidant effects," Life Sciences, vol. 77, no. 17, pp. 2166-2178, 2005.

[27] M. Raffi, F. Hussain, T. M. Bhatti, J. I. Akhter, A. Hameed, and M. M. Hasan, "Antibacterial characterization of silver nanoparticles against E. coli ATCC-15224," Journal of Materials Science and Technology, vol. 24, no. 2, pp. 192-196, 2008.

[28] S. Schultz, D. R. Smith, J. J. Mock, and D. A. Schultz, "Singletarget molecule detection with no bleaching multicolor optical immunolabels," Proceedings of the National Academy of Sciences of the United States of America, vol. 97, pp. 996-1001, 2000.

[29] I. Sondi and B. Salopek-Sondi, "Silver nanoparticles as antimicrobial agent: a case study on E. coli as a model for Gramnegative bacteria," Journal of Colloid and Interface Science, vol. 275, no. 1, pp. 177-182, 2004.

[30] G. A. Martinez-Castanon, N. Niño-Martínez, F. MartínezGutierrez, J. R. Martínez-Mendoza, and F. Ruiz, "Synthesis and antibacterial activity of silver nanoparticles with different sizes," Journal of Nanoparticle Research, vol. 10, no. 8, pp. 1343-1348, 2008. 

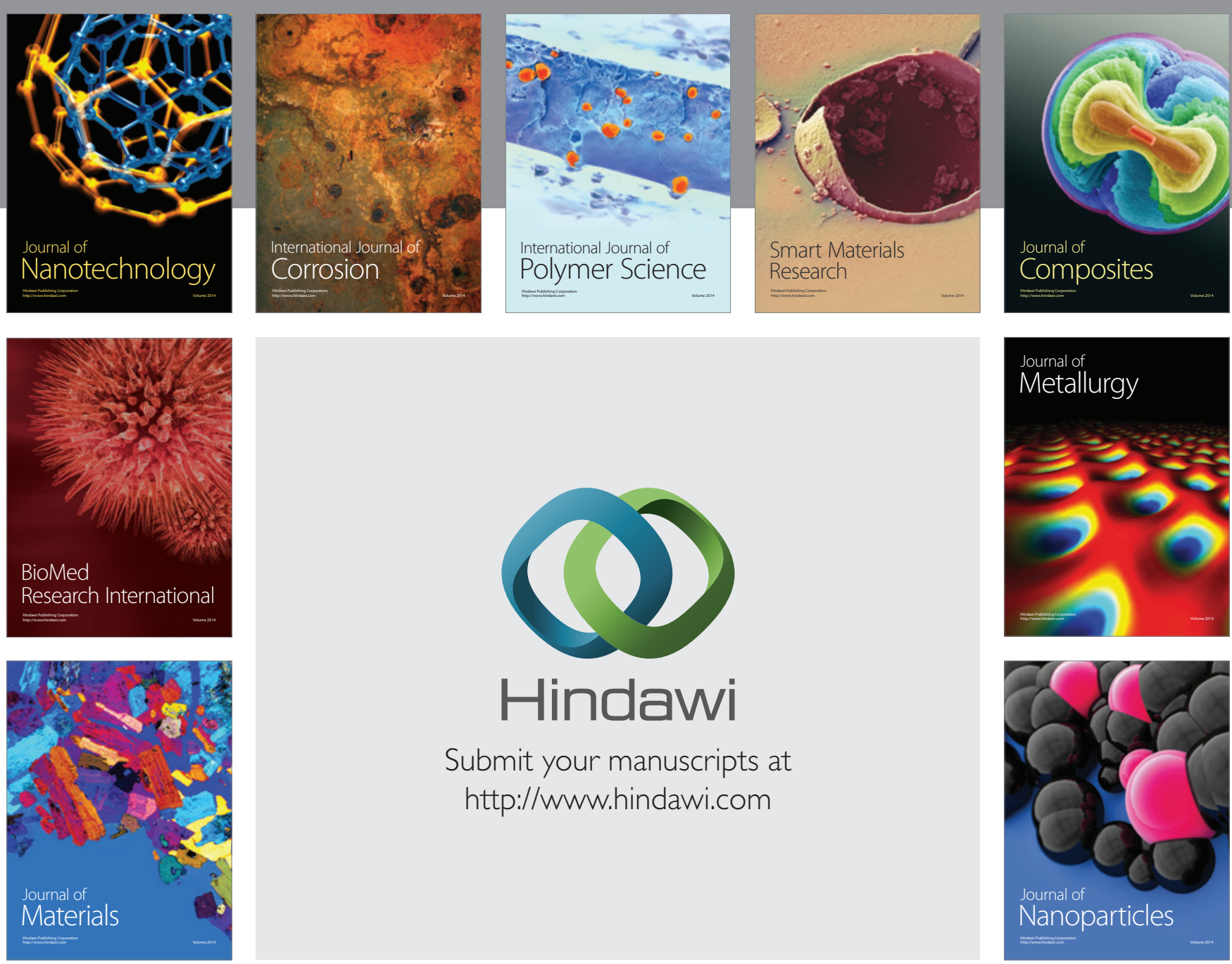

Submit your manuscripts at http://www.hindawi.com
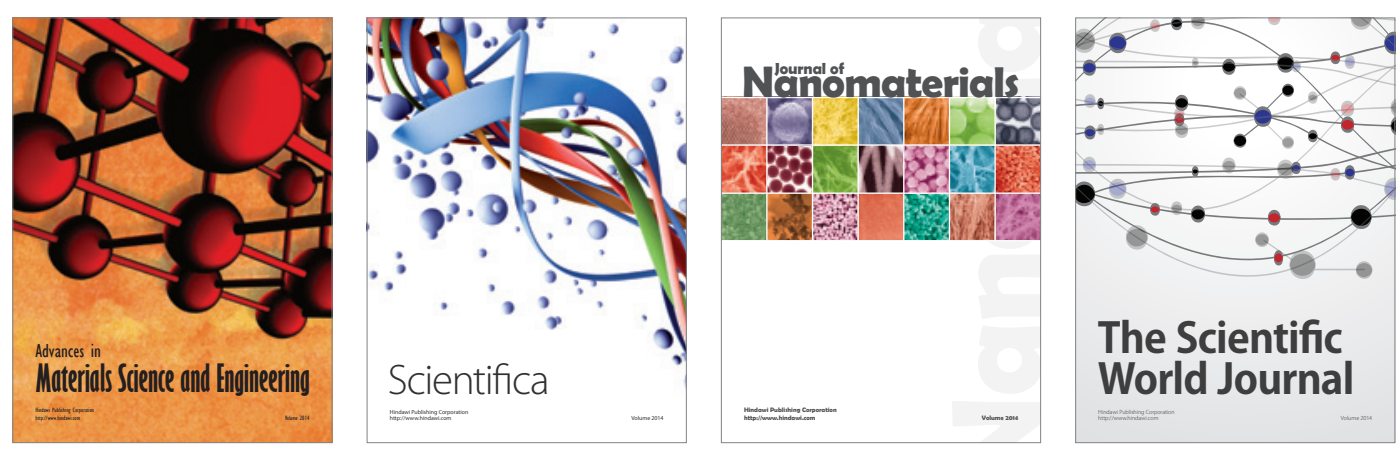

\section{The Scientific World Journal}
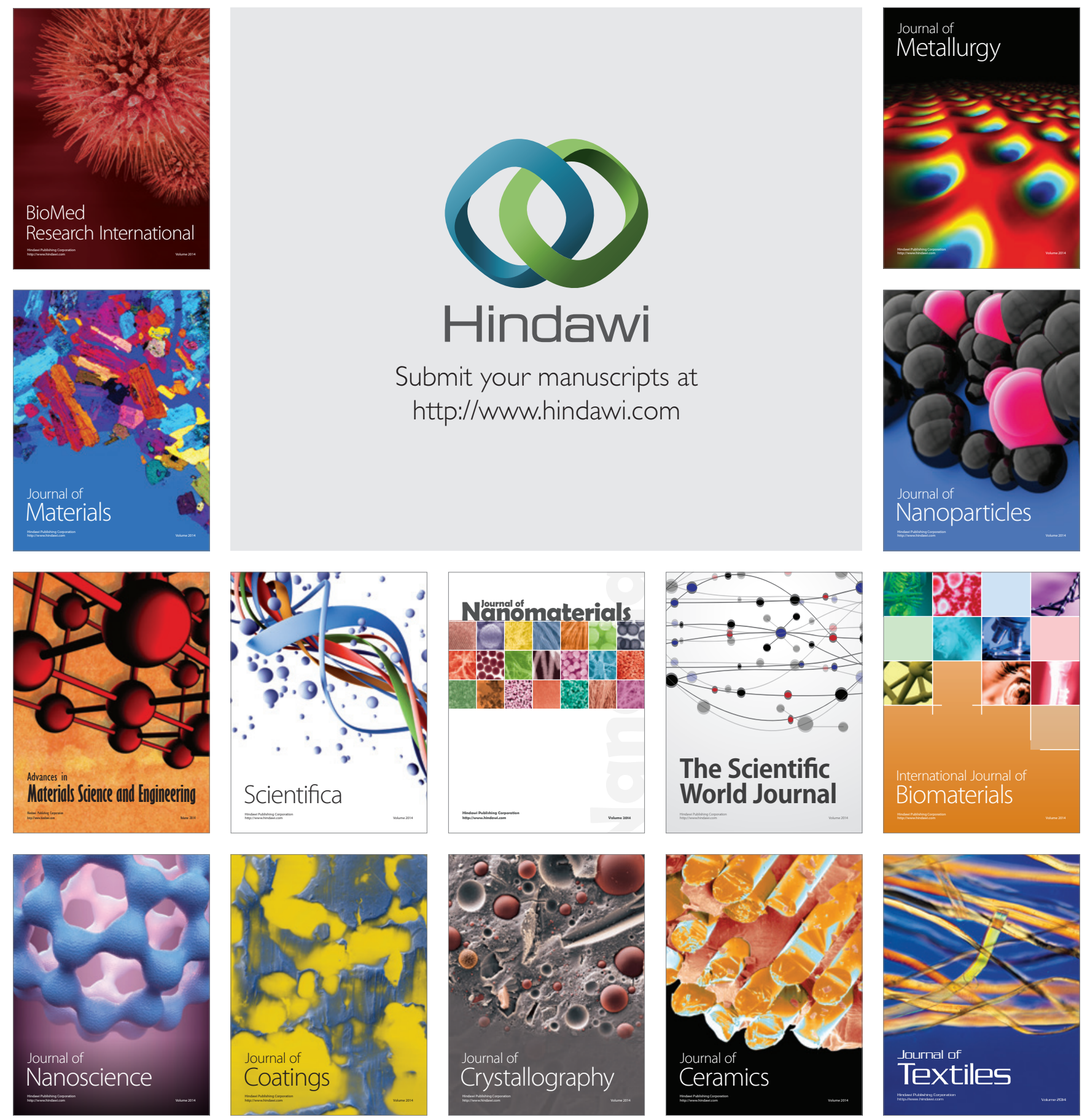